\title{
RAMAN AND X-RAY FLUORESCENCE TO IDENTIFY COLORS OF THE GERMAN HYPERINFLATION STAMPS OF THE 1923 COLLECTION
}

\author{
J.S. GÓMEZ-JERIA ${ }^{l *}$, M.M. CAMPOS-VALLETTE ${ }^{1}$, E.A.CARRASCO-FLORES ${ }^{1}$ AND S. GUTIÉRREZ V. ${ }^{2}$ \\ ${ }^{I}$ Universidad de Chile, Facultad de Ciencias, Depto. Química, POBox 653, Santiago, Chile. \\ ${ }^{2}$ Laboratorio de Análisis e Investigaciones Arqueométricas (LAIA), Instituto de Alta Investigación, Universidad de Tarapacá, Arica-Chile.
}

\begin{abstract}
Colors of a collection set of postage stamps dated 1923 and corresponding to the hyperinflationary period of the German economy were identified with Raman and $\mathrm{X}$-ray fluorescence (XRF) spectroscopies. Molecular systems associated to the blue, green and yellow colours were characterized. Blue colour is Prussian blue $\left(\mathrm{Fe}_{4}\left[\mathrm{Fe}(\mathrm{CN})_{6}\right]_{3}\right)$ and the green colour resulted to be a combination of Prussian blue and the yellow/orange pigment $\left(\mathrm{PbCrO}_{4}\right)$ or a yellow $\beta$-naphthol like monoazopigment. The $\mathrm{XRF}$ data suggest that $\mathrm{ZnO}$ was used as filler.
\end{abstract}

Keywords: Archaeophilately, German hyperinflation postage stamps, forgery, Raman spectrum, XRF, $\beta$-naphthol azopigments, Prussian blue, crocoite, zinc oxide.

\section{INTRODUCTION}

The first postage stamp became available for purchase in Great Britain during 1 May 1840. From then, what is depicted on postage stamps has become one of the faces of what a particular State wants to show to the rest of the world ${ }^{1-3}$. Some stamp drawings, such as maps, can be used as a form of propaganda, especially when some foreign territories are coveted ${ }^{4}$. One of the stamp components is the denomination (the inscribed value of a stamp). This inscribed value is of interest because sometimes it is changed by overprinting the stamp with a new value. The reasons can be several: military occupation, inflation, change of currency, change of political regime, taxes, etc. Overprints have been a fertile area of work for counterfeiters ${ }^{5}$. The first postage stamps were not printed for last forever. Even that stamp collection began little after $1840{ }^{6}$, the known number of some of them is so small that their commercial value is very high. During the $19^{\text {th }}$ century a group of expert forgers printed many stamps of almost the entire world (for example Giovanni de Sperati printed-forged so top quality stamps that they were declared by experts to be genuine). The interest of science in the analysis of postage stamps is probably a derivation of the general analysis of parchments and papers for restoration and conservation ${ }^{7-11}$. Stamps adhesive was the object of earlier studies ${ }^{12,13}$. The first papers employed nondestructive techniques to analyze expensive stamps or to build databases ${ }^{14-22}$. Nevertheless, there is another way to approach the study of stamps: the use of destructive methods. Many collectors, due to a mishandling of postage stamps, damage them in such a way that they cease to be a collectable object and are usually thrown away. This is the material that can be used with destructive methods. With these kinds of materials or of stamps that are known to exist millions of copies we carried out our first investigations ${ }^{6,23,24}$. One of our papers dealt with an infrared and SEM study of the margins of some German hyperinflation postage stamps ${ }^{6}$. This contribution deals with the identification of colors in inks of postage stamps produced during the hyperinflation period in the Weimar Republic (Germany), by using the Raman and XRF techniques. In order to have an idea of such period it is interesting to consign that, for example, for a domestic letter of less than 20 grams, a citizen must pay 20 Marks in January 15, 1923 and 50,000,000,000 Marks in December 12, 1923 25. Raman microscopy allows establishing the authenticity or forgeries of postage stamps; this spectroscopic technique is non-invasive, rapid and effective and then useful to identify and structurally characterize ink pigments, papers and eventually cancel marks. A general profile of the elements in the analyzed stamps is obtained from a portable XRF apparatus.

\section{EXPERIMENTAL}

\section{Stamps collection}

Eight stamps of a definitive series of hyperinflation stamps were selected. The samples corresponded to mint never hinged stamps. Fig. 1 shows the stamps along with their identification following the Michel Deutschland Spezial Katalog 26 .

*Corresponding author email: facien05@uchile.cl

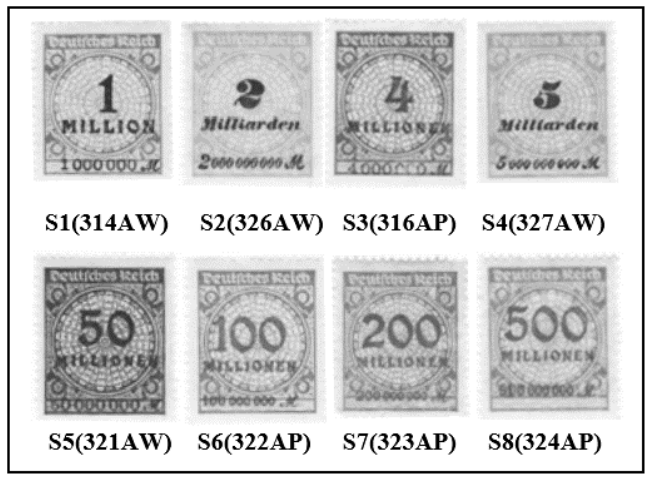

Figure 1. German postage stamps used in this study. From left to right and top to bottom: S1 to S8, including their identification.

\section{Raman measurements}

Stamps were placed onto a microscopy slide and the Raman spectrum was recorded using a Renishaw Raman Microscope System RM1000 equipped with a diode laser providing the $785 \mathrm{~nm}$ line, a Leica microscope, an electrically cooled CCD (charge coupled device) detector and an edge filter to eliminate elastic scattering. Several places in each stamp were scanned; several of them displayed huge fluorescence hiding the Raman spectrum. The most representative spectrum with the best signal/noise ratio was chosen. No baseline corrections or spectral smoothing procedures were performed. The spectra were obtained using a 50x objective. The laser power was set $1-10 \mathrm{~mW}$; with a resolution of $4 \mathrm{~cm}^{-1}$ collecting 1-5 scans of 10-30 s each. Spectra were recorded in the $150-3200 \mathrm{~cm}^{-1}$ region. Spectral scanning conditions were chosen to avoid sample degradation and photodecomposition. Spectra are displayed in Figures 2 to 9 .

\section{XRF measurements}

XRF spectra were recorded with a portable XRF Bruker Tracer III-SD apparatus with a detector fitted $10 \mathrm{~mm}^{2}$ XFlash ${ }^{\circledR}$ SDD, Peltier cooled and equipped with an X-ray Tube $\mathrm{Rh}$ target; max voltage $40 \mathrm{keV}$. The specifications for this study were high voltage $40 \mathrm{keV}$ of energy, $37.8 \mu \mathrm{A}$ of intensity, an acquisition time of 200 seconds. Data were collected and plotted using Tracer software S1PXRF 3.8.3 and ARTAX7. All results obtained were semiquantitative. For comparison all results were standardized as areas of each element. Standardization was performed through the following formula: $\mathrm{S}=\mathrm{A} / \Sigma \mathrm{A}$, where $\mathrm{S}=$ Net Standarized, $\mathrm{A}=$ Net and $\Sigma \mathrm{A}=$ Sum of Net. Table 1 contains the XRF data. Stamps were placed directly on the electron beam of the $\mathrm{XRF}$ apparatus. The spot of the laser has a $0.8 \mathrm{~cm}$ diameter. Measurements were performed directly in the centre of the stamp were the colour was intense the most. 
Table 1. X ray fluorescence (XRF) standardized data*.

\begin{tabular}{|c|c|c|c|c|c|c|c|c|}
\hline Stamp & Al & $\mathbf{S i}$ & $\mathbf{P}$ & $\mathbf{S}$ & $\mathbf{K}$ & $\mathrm{Ca}$ & $\mathbf{T i}$ & $\mathrm{Cr}$ \\
\hline S1 & 0.00468 & 0.00879 & 0.00482 & 0.02523 & 0.02208 & 0.03898 & n.d.* & 0.03800 \\
\hline S2 & 0.00348 & n. d. & n.d. & n.d. & 0.01480 & 0.09438 & 0.01672 & 0.06680 \\
\hline S3 & 0.00947 & 0.01821 & n.d. & n.d. & 0.03540 & 0.06900 & n.d. & 0.22656 \\
\hline S4 & 0.01044 & n.d. & 0.01307 & n.d. & 0.02833 & 0.28398 & n.d. & 0.14402 \\
\hline S5 & 0.00674 & n.d. & n. d. & n.d. & 0.02544 & 0.17963 & 0.02689 & 0.13432 \\
\hline S6 & 0.00618 & 0.01153 & 0.00507 & 0.02226 & 0.02253 & 0.05231 & n.d. & n. d. \\
\hline S7 & 0.01255 & 0.02746 & n.d. & n.d. & 0.04256 & 0.10005 & n.d. & 0.15937 \\
\hline S8 & 0.00955 & n.d. & 0.01379 & n.d. & 0.03063 & 0.24278 & 0.03993 & 0.15876 \\
\hline Stamp & Mn & $\mathrm{Fe}$ & $\mathbf{N i}$ & $\mathrm{Cu}$ & $\mathbf{Z n}$ & $\mathbf{P b}$ & $\mathrm{Sr}$ & $\mathbf{B a}$ \\
\hline S1 & 0.02645 & 0.08826 & 0.04205 & 0.03656 & 0.4181 & 0.02837 & 0.01135 & 0.04085 \\
\hline S2 & n.d. & 0.07860 & 0.03403 & 0.03162 & 0.58885 & 0.05766 & n.d. & n.d. \\
\hline S3 & n.d. & 0.10810 & 0.07168 & 0.06308 & 0.04312 & 0.20802 & 0.02389 & 0.09516 \\
\hline S4 & n.d. & 0.08823 & 0.07691 & 0.07795 & 0.05434 & 0.15322 & n.d. & 0.03907 \\
\hline S5 & n.d. & 0.12674 & 0.05437 & 0.05194 & 0.22560 & 0.14681 & n.d. & n. d. \\
\hline S6 & n.d. & 0.0670975 & 0.0461309 & 0.04197 & 0.63517 & 0.01514 & 0.01327 & 0.04334 \\
\hline S7 & n.d. & 0.10886 & 0.08984 & 0.09433 & 0.05398 & 0.15716 & 0.02727 & 0.09112 \\
\hline S8 & n.d. & 0.08398 & 0.0842 & 0.07413 & 0.05000 & 0.17853 & n.d. & n.d. \\
\hline
\end{tabular}

*Standardized data of the area under the curve of each element.

$*$ n.d. $=$ not detected.

\section{RESULTS AND DISCUSSION}

\section{Raman spectra}

The code sample, color and pigments found in the stamps are displayed in Fig.1. The wavenumbers and the bands assignment are collected in Table 2. The Raman bands assignment of the samples is based on general Raman data ${ }^{27-29}$, and mainly from related works by Imperio et al ${ }^{18,30,31}$. The spectra are shown as obtained and are illustrated with the stamp picture in Figs. 2 to 9 .

S1 1 Million. This stamp displays a blue color, Fig. 2. Strong bands at 2166, 534 and $274 \mathrm{~cm}^{-1}$, the medium band at $2104 \mathrm{~cm}^{-1}$ and the weak bands at 2137 , 957 and $215 \mathrm{~cm}^{-1}$ are ascribed to Prussian blue (PB, $\left.\mathrm{Fe}_{4}\left[\mathrm{Fe}(\mathrm{CN})_{6}\right]_{3}\right)$. The bands at 2166 and $2104 \mathrm{~cm}^{-1}$ are due to $\nu \mathrm{C} \equiv \mathrm{N}$ vibrations. The $\mathrm{XRF}$ data, in Table 1 , are consistent with the presence of $\mathrm{Fe}$; however, the $\mathrm{Zn}$ element is abundant which suggests that it could be used as filler in the oxide form. If it is $\mathrm{ZnO}$ the corresponding $E_{2}$ and $A_{1}$ bands should appear at around 433 and $574 \mathrm{~cm}^{-1}$, respectively ${ }^{32}$, which are not evident in the spectrum of the stamp.

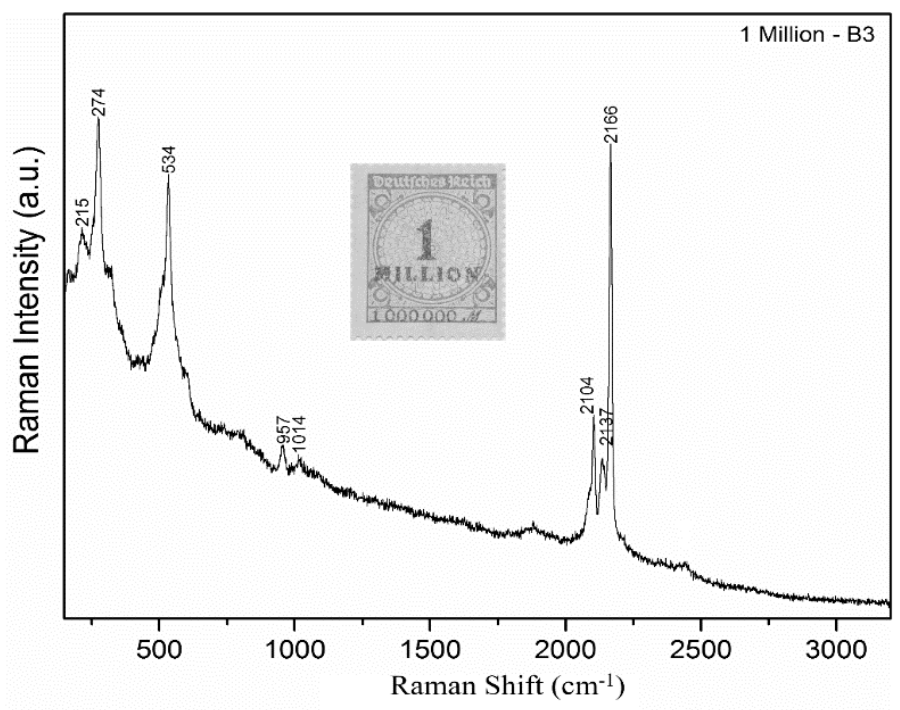

Figure 2. Raman spectrum of the stamp with denomination of 1 Million.
S2 2 Milliarden. Raman data were obtained only for the number 2 character area (denomination value) of this stamp, Fig. 3; this area displays a bluish green colour and the registered spectrum indicates the presence mainly of Prussian blue. The XRF data, Table 1, obtained from the background indicate the presence of $\mathrm{Zn}, \mathrm{Ca}, \mathrm{Fe}, \mathrm{Cr}$ and $\mathrm{Pb}$. No Raman spectrum was obtained for the yelloworange coloration area.

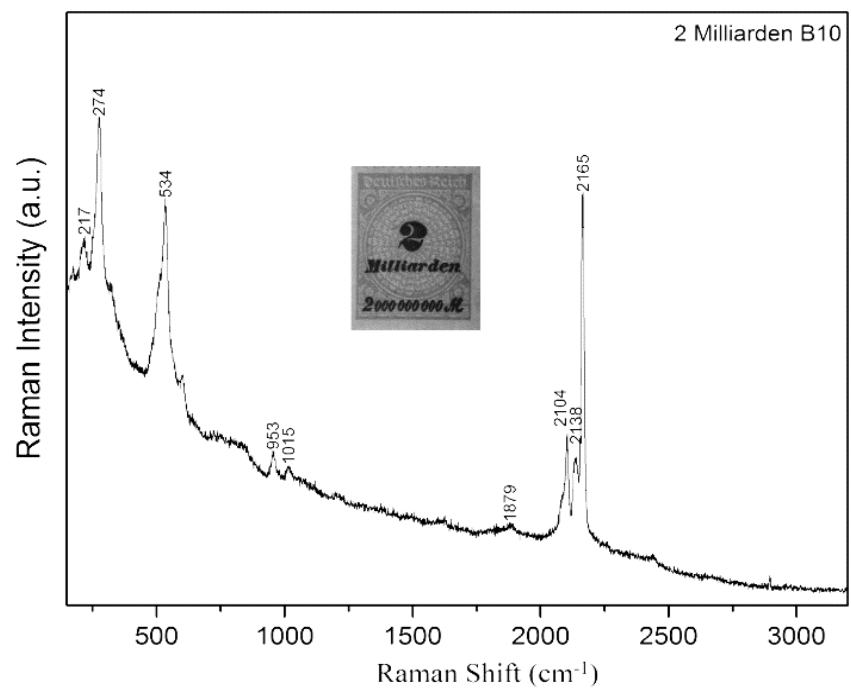

Figure 3. Raman spectrum of the stamp with denomination of 2 Milliarden

S3 4 Millionen. The stamp displays a green color, Fig. 4. The Raman signals of Prussian blue are clearly observed in the spectrum. Other bands particularly those at 844 and $332 \mathrm{~cm}^{-1}$ are ascribed to the yellow/orange pigment $\mathrm{Pb}_{2} \mathrm{OCrO}_{4}$ or $\mathrm{PbCrO}_{4}{ }^{14}$; both bands are due to vibrations of the chromate ion $\mathrm{CrO}_{4}{ }^{2-}$. The database from RRUFF ${ }^{29}$ indicates that both bands are coincident with the crocoite salt that is $\mathrm{PbCrO}_{4}$. XRF data, Table 1, indicates the presence of $\mathrm{Cr}, \mathrm{Pb}$ and $\mathrm{Fe}$, thus supporting the proposed molecular systems. The observed green colour is the result of the human low optical resolution when combining yellow and blue colours. By using the 100X microscope we have identified small orange and blue particles which Raman spectra indicated the presence of chrome orange and Prussian blue, respectively. 


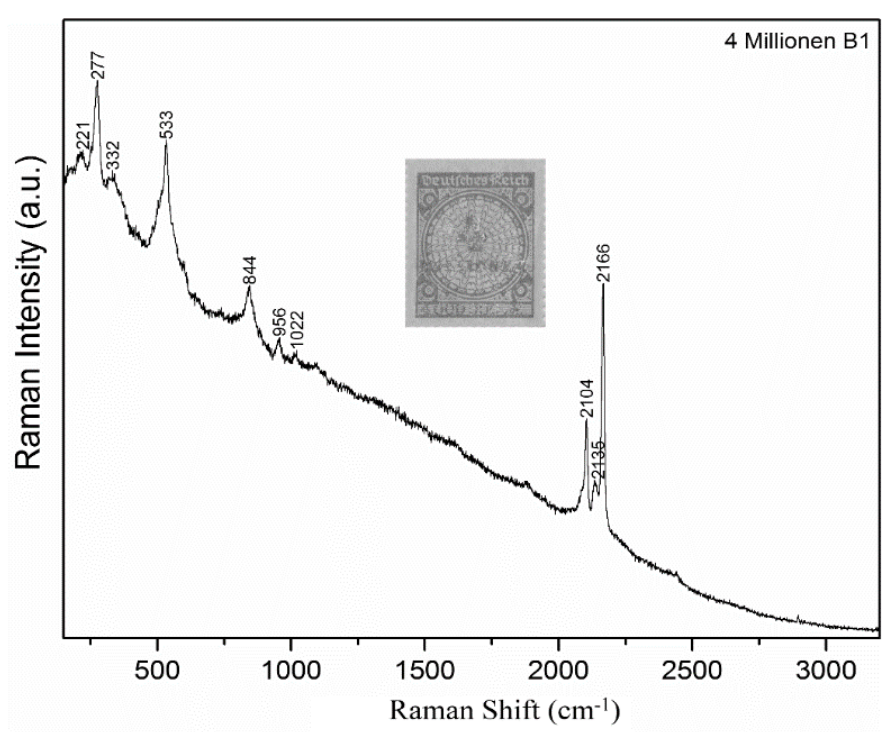

Figure 4. Raman spectrum of the stamp with denomination of 4 Millionen.

S4 5 Milliarden. Yellow components dominate the stamp colour Fig. 5. The spectrum displays general weak signals. Prussian blue profile is recognized through the bands at 2170, 2105 and about $280 \mathrm{~cm}^{-1}$. The medium and weak medium bands at 845 and $359 \mathrm{~cm}^{-1}$ are consistent with the presence of the yellow/orange pigment $\mathrm{PbCrO}_{4}$. Additional very weak bands at 1331, 1210 and $1111 \mathrm{~cm}^{-1}$ could correspond to a monoazopigment $\beta$-naphthol 1-(4-methyl-2nitrophenylazo)-2-naphthol following Scherrer et al ${ }^{28}$. The band at $407 \mathrm{~cm}^{-1}$ should correspond to the azopigment. XRF data, Table 1, indicate $\mathrm{Pb}, \mathrm{Cr}$ and $\mathrm{Fe}$ consistent with the proposed molecular systems. Ca is also determined by XRF which could be associated with the stamp support or the lake condition of the monoazopigment. However, Raman signals of any pigment or extender based on calcium were not observed.

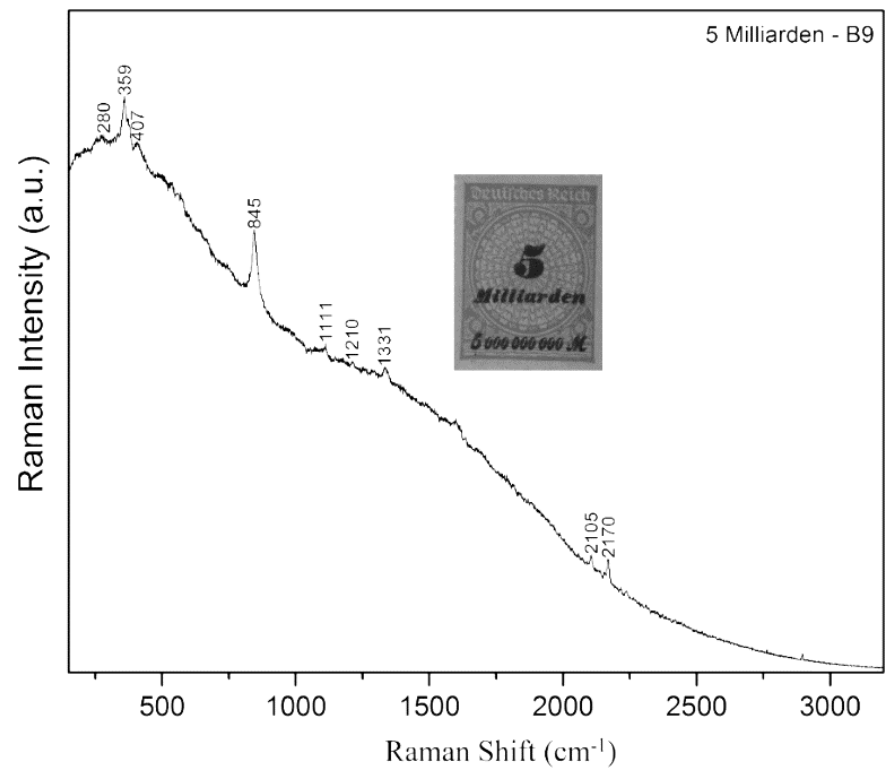

Figure 5. Raman spectrum of the stamp with denomination of 5 Milliarden.

S5 50 Millionen. This stamp displays a light green color, Fig. 6. The Raman signals indicate the existence of Prussian blue and the monoazopigment $\beta$ naphthol type with the already discussed bands at 1331,1213 and $1112 \mathrm{~cm}^{-1}$ and the additional now clearly observed bands at 762,412 and $371 \mathrm{~cm}^{-1}$; these additional bands could be a new information to precise the real monoazopigment involved. If the azopigment is a $\beta$-naphthol compound, then one should observe the amide III band at $1258 \mathrm{~cm}^{-1}$ (discriminate signal) which is not the case in the present research. Thus, a probable structure could be the naphthol azopigment lake with $\mathrm{Ca}^{2+30}$.
$\mathrm{Ca}$ is found (XRF, Table 1) in all stamps where this azopigment is identified. Then, the stamp light green colour observed should be originated from a yellow and blue components combination, being the blue color corresponding definitely to Prussian blue.

The yellow component should necessarily come from a yellow $\beta$-naphthol lake monoazopigment ${ }^{28}$. Raman signals corresponding to the possible presence of the yellow $\mathrm{PbCrO}_{4}$ pigment at about 850 and $360 \mathrm{~cm}^{-1}$ are not observed, even though the XRF data indicate the presence of $\mathrm{Cr}$ and $\mathrm{Pb}$.

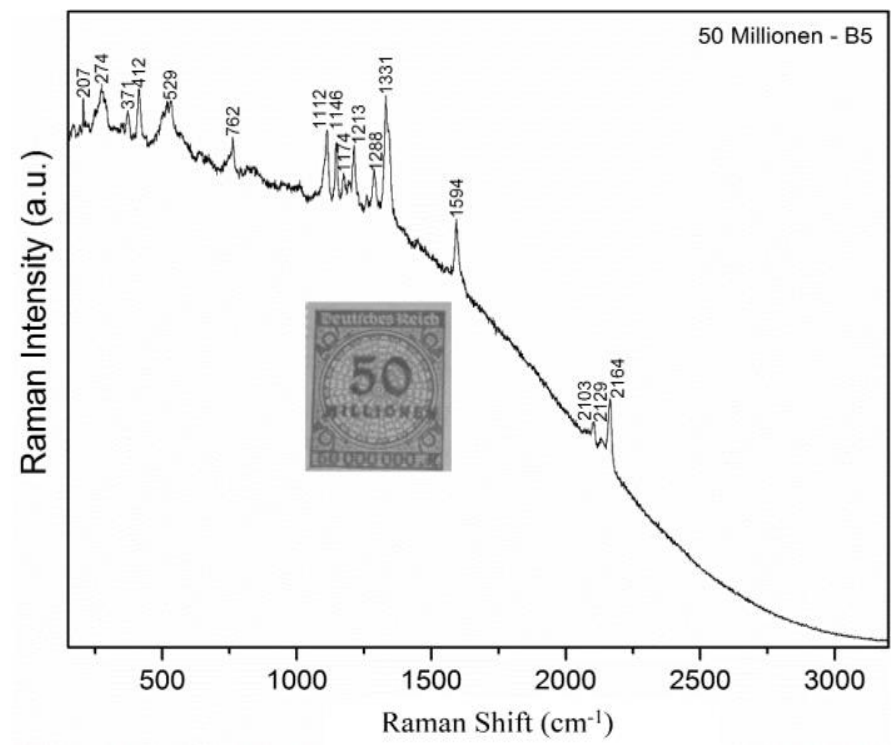

Figure 6. Raman spectrum of the stamp with denomination of 50 Millionen.

S6 100 Millionen. This stamp, Fig. 7, displays a green dark color. The Raman signals are rather weak profile indicating only the presence of Prussian blue. The $\mathrm{XRF}$ data, Table 1, indicates mainly $\mathrm{Zn}$, probably the filler used as $\mathrm{ZnO}$.

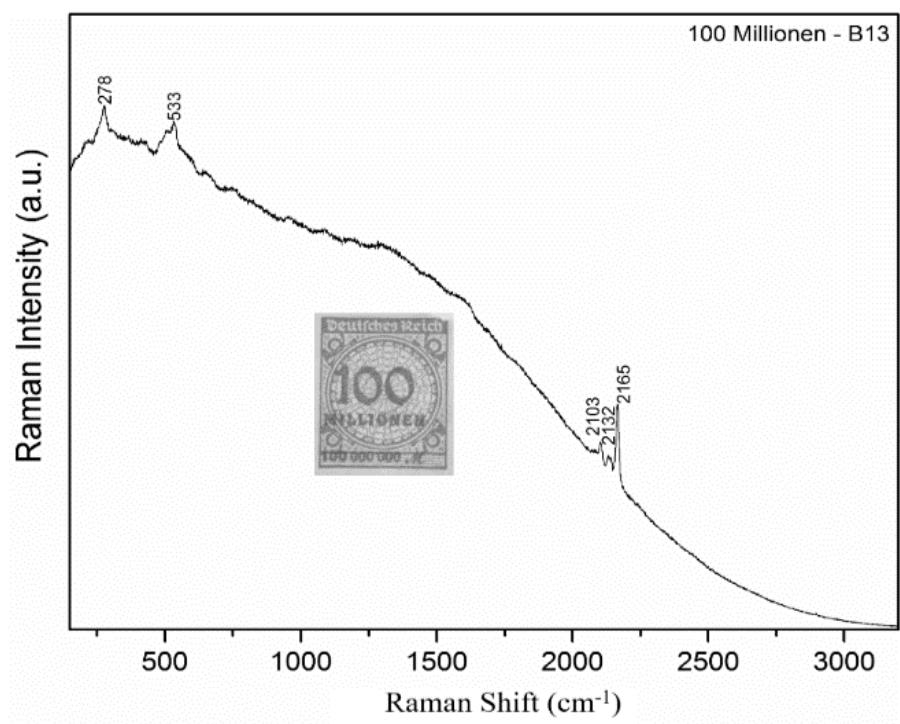

Figure 7. Raman spectrum of the stamp with denomination of 100 Millionen.

S7 200 Millionen. The stamp is brown, Fig. 8. This sample displays the clearest spectrum of the series, being Prussian blue, $\mathrm{PbCrO}_{4}$ and an azopigment easily recognized. In relation to the azopigment, the bands at 1595 and $760 \mathrm{~cm}^{-1}$ are assigned to the benzene quadrant stretching and the naphthalene moiety, respectively. The strong signal at $1332 \mathrm{~cm}^{-1}$ is attributed to an aromatic nitro fragment; the $v_{\text {sym }} \mathrm{CN}$ mode corresponds to the band at $1113 \mathrm{~cm}^{-1}$. The very weak band around $1450 \mathrm{~cm}^{-1}$ is attributable to the $v \mathrm{~N}=\mathrm{N}$ mode. $\mathrm{Pb}, \mathrm{Cr}$ and $\mathrm{Fe}$ are the most abundant components in the XRF data, Table $1 . \mathrm{Zn}$ as component of the filler is less abundant. 


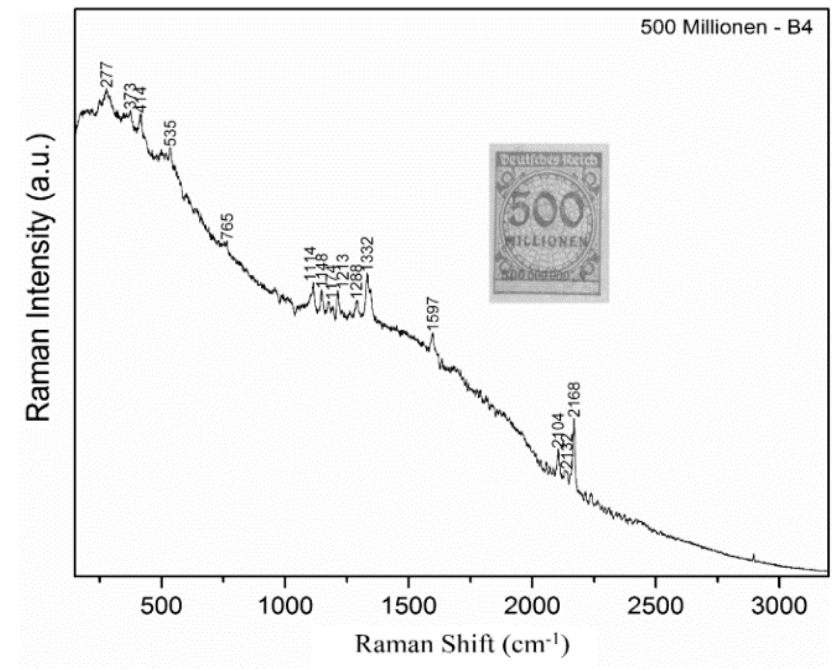

Figure 8. Raman spectrum of the stamp with denomination of 200 Millionen.

S8 500 Millionen. This stamp displays a light green color, Fig. 9. Only Prussian blue and a yellow $\beta$-naphthol lake monoazopigment were identified. $\mathrm{Pb}$ and $\mathrm{Ca}$ are indicated in the XRF data, Table 1. No signals from $\mathrm{Pb} \mathrm{CrO}_{4}$ were observed.

Table 2. Stamp code, wavenumbers $\left(\mathrm{cm}^{-1}\right)$ and bands assignment.

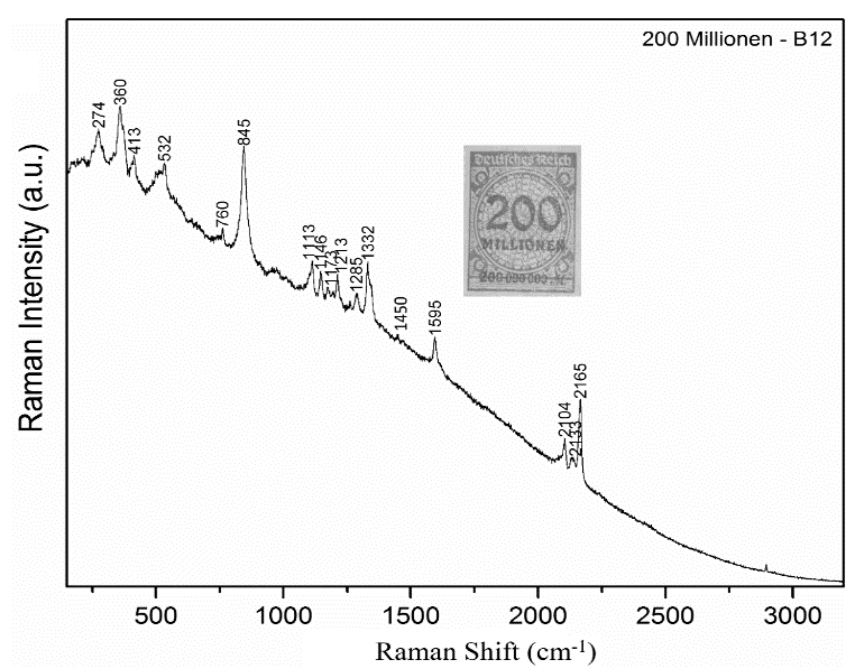

Figure 9. Raman spectrum of the stamp with denomination of 500 Millionen.

Finally, a résumé of the Raman bands wavenumbers of each stamp and the molecular systems or chemical moieties associated to the observed different colours is given in Table 2 .

\begin{tabular}{|c|c|c|c|c|c|c|c|c|}
\hline S1 & S2 & S3 & S4 & S5 & S6 & S7 & S8 & Assignment \\
\hline 215 & 217 & 221 & & & & & & Prussian blue \\
\hline \multirow[t]{6}{*}{274} & 274 & 277 & 280 & 274 & 278 & 274 & 277 & Prussian blue \\
\hline & & 332 & & & & & & $\mathrm{PbCrO}_{4}$ \\
\hline & & & 359 & & & 360 & & $\mathrm{PbCrO}_{4}$ \\
\hline & & & & 371 & & & 373 & Azopigment \\
\hline & & & 407 & & & & & Azopigment \\
\hline & & & & 412 & & 413 & 414 & Azopigment \\
\hline \multirow[t]{3}{*}{534} & 534 & 533 & & 529 & 533 & 532 & 535 & Prussian blue \\
\hline & & & & 762 & & 760 & 765 & Naphthalene \\
\hline & & 844 & 845 & & & 845 & & $\mathrm{PbCrO}_{4}$ \\
\hline \multirow[t]{9}{*}{957} & 953 & 956 & & & & & & Prussian blue \\
\hline & & & 1111 & 1112 & & 1113 & 1114 & Azopigment \\
\hline & & & & 1146 & & 1146 & 1148 & Azopigment \\
\hline & & & & 1174 & & 1173 & 1174 & Azopigment \\
\hline & & & 1210 & 1213 & & 1213 & 1213 & Azopigment \\
\hline & & & & 1288 & & 1285 & 1288 & Azopigment \\
\hline & & & 1331 & 1331 & & 1332 & 1332 & Azopigment \\
\hline & & & & & & 1450 & & $v \mathrm{~N}=\mathrm{N}$ \\
\hline & & & & 1594 & & 1595 & 1597 & Benzene \\
\hline 2104 & 2104 & 2104 & 2105 & 2103 & 2103 & 2104 & 2104 & Prussian blue \\
\hline 2137 & 2138 & 2135 & & 2129 & 2132 & 2133 & 2132 & Prussian blue \\
\hline 2166 & 2165 & 2166 & 2170 & 2164 & 2165 & 2165 & 2168 & Prussian blue \\
\hline
\end{tabular}

\section{CONCLUSIONS}

Coloured molecular components were identified in stamps belonging to the collection set of German postage stamps dated 1923 from the microRaman technique. $\mathrm{X}$ ray fluorescence (XRF) data allowed complement the identification of the chemical elements of the colouring molecular systems used; the $\mathrm{Zn}$ element is abundant in stamps S1, S2, S5, S6 which suggests that it could be used as filler in the oxide form. The expected $\mathrm{ZnO}$ Raman bands are not evident in the spectrum of the stamp. There are differences among all stamps depending on the shade of the color, i.e. on the amount of ink used in the manufacturing process and or on the ageing natural processes. Green colour resulted to be a combination of Prussian blue $\left(\mathrm{Fe}_{4}\left[\mathrm{Fe}(\mathrm{CN})_{6}\right]_{3}\right)$ and the yellowish pigment $\left(\mathrm{PbCrO}_{4}\right)$, and in some cases a yellow $\beta$-naphthol lake monoazopigment. In all the samples the main element of the ink is iron $(\mathrm{Fe})$ and in some stamps there is a significant amount of calcium (Ca). In fact, iron and calcium showed a direct and strong correlation in the analysis.

\section{REFERENCES}

1. P. Raento and S.D. Brunn. Visualizing Finland postage stamps as political messengers. Geografiska Annaler: Series B, Human Geography, 87 (2005) $145-164$.

2. S.D. Brunn. Stamps as iconography: Celebrating the independence of new European and Central Asian states. GeoJournal, 52 (2000) 315-323.

3. D. Gentleman. Stamps as signs. RSA Journal, 143 (1995) 68-70.

4. B. Davis. Maps on Postage Stamps as Propaganda. The Cartographic Journal, 22 (1985) 125-130.

5. T. Lewes and E.L. Pemberton. Forged stamps: how to detect them. Colston and Son: Edimburgh - https://archive.org/, 1863; p 36, 39 p.

6. J.-S. Gómez-Jeria, E. Clavijo, J. Cárcamo-Vega and S. Gutierrez. An infrared and SEM study of the margins of some German hyperinflation postage stamps. Research Journal of Pharmaceutical, Biological and Chemical Sciences, 9 (2018) 870-892. 
7. S.H. Zeronian and H.L. Needles. Historic Textile and Paper Materials II. American Chemical Society: 1989; Vol. 410, p 276.

8. M. Derrick. Evaluation of the state of degradation of dead sea scroll samples using FT-IR spectroscopy. Book Paper Group Annual, (1991) 10.

9. G. Righini, A.L. Segre, G. Mattogno, C. Federici and P.F. Munafò. An X-ray photoelectron spectroscopic study of ancient paper and its deterioration. Naturwissenschaften, 85 (1998) 171-175.

10. M.C. Sistach, N. Ferrer and M.T. Romero. Fourier Transform Infrared Spectroscopy Applied to the Analysis of Ancient Manuscripts. In Restaurator, 19 (1998) 173.

11.M.R. Derrick, D. Stulik and J.M. Landry. Infrared spectroscopy in conservation science. Getty Publications: 2000.

12. M. Poslusny and K.E. Daugherty. Nondestructive Adhesive Analysis on Stamps by Fourier Transform Infrared Spectroscopy. Applied Spectroscopy, 42 (1988) 1466-1469.

13. J.H.A. Wang. Versatile Analytical Method of Identifying Adhesive on Stamps by Specular-Reflectance Fourier Transform Infrared Spectroscopy. Applied Spectroscopy, 44 (1990) 447-450.

14. T.D. Chaplin, R.J.H. Clark and D.R. Beech. Comparison of genuine (18511852 AD) and forged or reproduction Hawaiian Missionary stamps using Raman microscopy. Journal of Raman Spectroscopy, 33 (2002) 424-428.

15. T.D. Chaplin, A. Jurado-López, R.J.H. Clark and D.R. Beech. Identification by Raman microscopy of pigments on early postage stamps: distinction between original 1847 and $1858-1862$, forged and reproduction postage stamps of Mauritius. Journal of Raman Spectroscopy, 35 (2004) 600-604.

1. 16 R.J. Weiss and D.R. Chartier. Fakebusters II: Scientific Detection of Fakery in Art and Philately. World Scientific: 2004; Vol. 4.

16. K. Castro, B. Ábalos, I. Martínez-Arkarazo, N. Etxebarria and J.M. Madariaga. Scientific examination of classic Spanish stamps with color error, a non-invasive micro-Raman and micro-XRF approach: The King Alfonso XIII (1889-1901 "Pelón”) 15 cents. J. Cultural Heritage, 9 (2008) 189-195.

17. E. Imperio, G. Giancane and L. Valli. Spectral Database for Postage Stamps by Means of FT-IR Spectroscopy. Analytical Chemistry, 85 (2013) 70857093.

18. E. Imperio, G. Giancane and L. Valli In Fourier transform infrared spectroscopy $($ FTIR) investigation focused on Italian postage stamps in the course of time, 3rd Workshop-Plasmi, Sorgenti, Biofisica ed Applicazioni, 2013; 2013; pp 49-52
19. H.G. Brittain. Attenuated Total Reflection Fourier Transform Infrared (ATR FT-IR) Spectroscopy as a Forensic Method to Determine the Composition of Inks Used to Print the United States One-cent Blue Benjamin Franklin Postage Stamps of the 19th Century. Applied Spectroscopy, 70 (2016) 128136.

20. J.J. Melendez-Perez, D.N. Correa, V.V. Hernandes, D.R. de Morais, R.B. de Oliveira, W. de Souza, J.M. Santos and M.N Eberlin. Forensic Application of X-ray Fluorescence Spectroscopy for the Discrimination of Authentic and Counterfeit Revenue Stamps. Applied Spectroscopy, 70 (2016) 1910-1915.

21.N.V. Schwab, J.A. Da-Col, P. Meyer, M.I.M.S. Bueno and M.N. Eberlin Energy Dispersive X-Ray Fluorescence Profile of Some Brazilian Postage Stamps. Journal of the Brazilian Chemical Society, 27 (2016) 1305-1310.

22. J.S. Gómez-Jeria and E. Clavijo A preliminary infrared study of the cellulose of some world stamps. Chemistry Research Journal, 2 (2017) 191-197.

23. J.S. Gómez-Jeria, E. Clavijo and Gutiérrez S. An Infrared and SEM study of the margins of some Estonian postage stamps. Research Journal of Pharmaceutical, Biological and Chemical Sciences, 9 (2018) 1258-1279.

24.B. Widdig. Culture and inflation in Weimar Germany. University of California Press: Berkeley, 2001; p xvi, 277 p.

25. Michel Deutschland-Spezial. Band 1. Schwaneberger: Unterschleißheim, 2016

26. D. Lin-Vien, N.B. Colthup, W.G. Fateley and J.G. Grasselli, The handbook of infrared and Raman characteristic frequencies of organic molecules, Elsevier, 1991.

27. N.C. Scherrer, Z. Stefan, D. Francoise, F. Annette and K. Renate, Spectrochim. Acta Part A: Molecular and Biomolecular Spectroscopy, 73 (2009) 505-524.

28. R. Downs, The RRUFF Project: an integrated study of the chemistry, crystallography, Raman and infrared spectroscopy of minerals, in: Program and abstracts of the $19^{\text {th }}$ general meeting of the international mineralogical association in Kobe, Japan. O03-13, 2006.

29. E. Imperio, G. Giancane and L. Valli, Analyst, 140 (2015) 1702-1710.

30. E. Imperio, E. Calò, L. Valli and G. Giancane, Vib. Spectrosc., 79 (2015) 52 58.

31. A. Ismail, M.J. Abdullah, J. King Saud Univ.-Sci., 25 (2013) 209-215. 